This item was submitted to Loughborough's Research Repository by the author.

Items in Figshare are protected by copyright, with all rights reserved, unless otherwise indicated.

\title{
Exploring the expectations of transport professionals concerning the future automobility system: Visions, challenges, and transitions
}

\section{PLEASE CITE THE PUBLISHED VERSION}

https://doi.org/10.1080/15568318.2016.1275891

\section{PUBLISHER}

(C) Taylor and Francis

\section{VERSION}

AM (Accepted Manuscript)

\section{PUBLISHER STATEMENT}

This work is made available according to the conditions of the Creative Commons Attribution-NonCommercialNoDerivatives 4.0 International (CC BY-NC-ND 4.0) licence. Full details of this licence are available at: https://creativecommons.org/licenses/by-nc-nd/4.0/

\section{LICENCE}

CC BY-NC-ND 4.0

\section{REPOSITORY RECORD}

Morton, Craig, Thomas Budd, Gillian Harrison, and Giulio Mattioli. 2019. "Exploring the Expectations of Transport Professionals Concerning the Future Automobility System: Visions, Challenges, and Transitions". figshare. https://hdl.handle.net/2134/28303. 


\title{
Exploring the Expectations of Transport Professionals Concerning the Future Automobility System: Visions, challenges and transitions
}

\author{
Authors \\ Craig Morton (Institute for Transport Studies, University of Leeds) * \\ Thomas Budd (Centre for Air Transport Management, Cranfield University) \\ Gillian Harrison (Joint Research Centre, European Commission) \\ Giulio Mattioli (Institute for Transport Studies, University of Leeds) \\ *correspondence author: c.morton@live.co.uk
}

\begin{abstract}
A mixture of potentially significant changes in technology, commercial structures and social practices are currently entering the automobility system. These changes have the potential to combine together and lead to a substantial shift in the manner in which society fuels, owns and makes use of its cars. This paper reports a research project which made use of focus groups to examine the narratives of British transport professionals concerning forthcoming developments in the automobility system. Specific attention was given to what the expectations for future change in automobility are, if these changes will likely lead to a transition towards a more sustainable system and the manner in which a transition of this nature could be facilitated. The oral testimony offered during the focus groups has been assessed qualitatively using thematic analysis. The results suggest that there is a commonly held view that the automobility system is entering a stage of flux which may lead to considerable changes in system configuration. However, the attainment of a sustainable transition for the system will likely be inhibited by a series of institutional, societal and physical barriers which may restrict system developments.
\end{abstract}

\section{Keywords}

Automobility System, Transport Futures, Sustainable Transition

\section{Reference}

Morton, C., Budd, T. M., Harrison, G., \& Mattioli, G. (2017). Exploring the expectations of transport professionals concerning the future automobility system: Visions, challenges, and transitions. International Journal of Sustainable Transportation, 11(7), 493-506.

https://doi.org/10.1080/15568318.2016.1275891 


\section{Introduction}

Car use has come to dominate the mobility system of almost all economically developed societies. In the UK, the last half century has witnessed an expansion in the vehicle kilometres travelled by car, van and taxi from 185 billion in 1963 to 638 billion in 2013, leading to a situation where over 83\% of all kilometres travelled are done so in these vehicles (Department for Transport, 2014). This expansion has been intertwined with a substantial growth of UK economic output whereby car use has led to and benefited from the increasing level of financial prosperity (Eddington, 2006). With the levels of car use having plateaued in the UK and other developed countries in the 21st century (Bastian et al. 2016), the present seems a suitable interval to consider what the future may hold for the car and whether or not its position of central importance in society will be reinforced or diminished. The intention of this paper is to qualitatively explore the current perceptions of British transport professionals concerning future expectations of the car based automobility system, how transitions in system configuration might occur, the challenges and mechanisms that shape it, and the outcomes which could be generated as part of a future vision of sustainable mobility.

Part of the widespread adoption of automobility stems from the significant functional capabilities cars offer (e.g. speed of movement and luggage capacity) and the relative advantage cars have in terms of these functional capabilities compared to alternative modes of transport. This relative advantage combines with issues related to the motorised landscape of the built environment and the format of social systems to generate a situation whereby automobility is firmly embedded into everyday practices (Featherstone, 2004; Urry, 2007; Banister and Anable, 2009). The importance of cars is also reinforced by the assignment of affective and symbolic value to them (Dittmar, 1992; Steg, 2005), with drivers having a tendency to consider their cars to be a source of positive emotion (Sheller, 2004; Kent, 2015), psychological stimulus (Gärling, et al. 2002) and a representation of their identity (Gatersleben, 2011).

The expansion of the automobility system has coincided with, and been supported by, sustained incremental enhancements to the technical performance of cars. However, the coming decades have the potential to witness a shift away from incremental improvement towards substantial evolution of the automobility system, driven by technical innovations and alterations in the social practices around car use (Kent and Dowling, 2013; Tran et al. 2013; Hopkins, 2016a). Focusing on the technical innovations, the introduction of low emission propulsion systems into the automotive market (e.g. electric and hydrogen vehicles) may lead to significant alterations in the way in which cars are fuelled 
and driven. These innovations in propulsion technology will likely coincide with the addition of more advanced information and communication technology (ICT) systems into cars allowing for a greater degree of automation in vehicle drive. Additionally, enhancements in ICT systems are improving the seamlessness of shared-vehicle schemes, allowing for flexible car access to be attained more easily (Cairns, 2011; Kley et al. 2011; Shaheen and Cohen, 2013). These technical innovations and an increasing awareness of the environmental and social consequences of the automobility system are generating a window of opportunity for a sustainable transition in the system's configuration (Kemp et al. 2012), which has already garnered significant academic attention (Geerlings et al. 2012).

The research reported in this paper aims to contribute to the ongoing discussion surrounding the concept of sustainable mobility by exploring the expectations of transport professionals regarding how automobility may develop in the future. The research draws from studies that discuss the sociotechnical system of automobility, the visions of its future and the potential for transitions in its structure. A series of focus groups were held with British transport professionals, to bring to light the current narratives of expertise in the field. These have been qualitatively assessed and synthesised into common themes. The paper highlights the various obstacles that might impede a sustainable transformation in automobility and how these obstacles might be addressed. Rather than seeking to be entirely comprehensive in its assessment of the issue, the paper offers a candid appraisal of the issues which are currently salient amongst transport professionals in regards to the future of automobility, although in the conclusion we provide a more critical discussion of the narratives of transport professionals and how they contribute (or not) to sustain the automobility system in its current form.

\section{Existing Literature}

The ubiquitous presence of car based mobility in everyday life in the developed world has led to substantial research activity on automobility. This section briefly discusses three prominent aspects of the topic in an effort to position the research presented in this paper. Firstly, the general concept of automobility is introduced, particularly in terms of how it operates as a system. This then leads to an overview of the future visions of automobility that have been developed in the literature and finally the transition pathways that may be followed to move towards these visions. 


\subsection{The Concept of Automobility}

The notion of automobility can be conceived as a marriage of two concepts (Ker and Tranter, 1997; Dowling and Kent, 2013). Firstly, autonomous agency which is enabled by the activation of technical artefacts that allows humans to transcend their physical limitations. Secondly, mobility which comprises the movement of something that has the capacity to move, such as humans around their environments. Important for the understanding of this research, these two concepts have now become almost entirely understood by the widespread use of the car, with Böhm et al. (2006) noting that "in contemporary societies, the car stands in place of automobility itself" (p. 4).

Cars have come to attain this position of dominance in society due in part to their ability to compress time and space and offer their drivers unbridled flexibility in their movement (Beckmann, 2001). The human landscape has developed to harness these flexibilities and produced a form of spatial organisation which seemingly necessitates the use of cars. Indeed, Featherstone $(2004$, p.2) notes that "social life has become locked into the modes of mobility that automobility generates and presupposes". Urry (2004) argues that the notion of automobility represents a complex system of assemblages which can be thought to contain a set of interrelated components. This system situates the car as the most conspicuous form of manufactured good in modern society and details the level of social status attached to car ownership and use in cultural discourse. This situation of cars is sustained through an intricate and powerful set of institutional arrangements which grants the system the right to impose significant charges on society and the environment. These components relate to the personal, social, institutional and environmental domains of life and demonstrate how the automobility system is intertwined with all aspects of modern existence.

Böhm et al. (2006) further develop the notion of automobility by conceptualising it as a regime in order to highlight its political character. This regime is comprised of three main elements which first positions the car as the superior state of mobility, second notes the diverse forms of power which underpin the regime and third highlights the connection between driving and self-actualisation. This interpretation of automobility is extended through an appreciation of the antagonisms which the regime produces. These antagonisms are described by Böhm et al. (.ibid) as side-effects and include the widespread problems association with the emission of global and local pollutants, the deaths and injuries generated by car use, the geopolitical tensions that surround the supply of transport fuel and the landscape transformations which the automotibility system imposes. Lyons (2012) extends Böhm et al.'s notion of automobility as a regime by describing it as a system of systems which exists within a complex domain of social practice. Lyons (ibid.) notes that attention is beginning to shift towards 
evaluating automobility against the conventional sustainability components of economic prosperity, environmental sustainability and social cohesion which are positioned as the overarching aspirations to address the system's current antagonisms.

Whilst the conceptions of automobility offered by Urry (2004), Böhm (2006) and Lyons (2012) share similarities, they each approach the topic from distinct directions. Rather than being mutually exclusive, these unique conceptualisations serve to highlight the intricacy of automobility, illustrating how the system represents a complex of social, political, technical and economic issues. The research presented in this paper does not attempt to format its own perspective of automobility, but rather considers the expectations of transport professionals regarding how automobility may evolve in the next few decades.

\subsection{The Future of Automobility}

While the application of trend extrapolation has tended to be the favoured approach to understanding likely changes in the level of automobility, Banister (2005) outlines how exploring visions of transport futures can be a valid alternative to conceptualising the dynamic in the structure of automobility. This view is shared by Goldman and Gorham (2006) who state the requirement for big ideas in urban transport in order to alter the evolutionary momentum and achieve a sustainable future. As part of this, there is a burgeoning debate on if mobility itself is the issue which society seeks to optimise or should the focus be more towards accessibility (Martens, 2012), which would require a different view of the future of automobility. Indeed, the application of visioning exercises appears to becoming popular in British policy, with Lyons (2012) detailing the use of horizon scanning strategies to understand the future of intelligent transport systems.

Describing two possible futures for the automobility system, Urry (2007) expresses his view that the system has the potential to either collapse as a result of catastrophic climate change and restrictions in oil supply or be sustained through the emergence of a nexus vehicle system. This nexus vehicle system shares similarities with Safdie's (1998) suggestion of an automobility system based on the provision of Utility Cars which are socially owned vehicles allowing on-demand access. Enoch (2015) progresses the ideas of Urry and Safdie by describing how the lines which currently distinguish the conventional transport modes of bus, taxi and car are blurring, due to a mixture of technology push and demand pull factors. 
Developing visions of the future for the automobility system assists in considering what the possible and desirable system states might be. Vergragt and Brown (2007) suggest that visioning is not enough on its own, and advocate the need for integration between multi-stakeholder visioning with scenario building, backcasting exercises and socio-technical experiments in order to re-think the system of personal mobility. Offering a combined assessment of this nature, Whitmarsh et al. (2009) make use of an Integrated Sustainability Assessment to explore expectations of sustainable mobility futures, demonstrating how collaborative approaches can be useful in the co-construction of visions which assist in empowering citizens and in the development of proposals that are more civically acceptable. Offering a less optimistic vision for the future mobility system, which is similar to Urry's (2007) view of potential system collapse, Moriarty and Honnery (2008) argue that the continued existence of a highmobility system based on private car ownership is dependent on technical advancements which are unlikely to achieve the required improvements in environmental sustainability. With the expiration of the existing automobility system viewed as being inevitable, Moriarty and Honnery (ibid.) propose an alternative low-mobility system which sees a reversion to active and public transit as a mechanism through which a system based on a socially and ecologically sustainable world-view could be attained.

Although Moriarty and Honnery (ibid.) effectively argue the case for a potential withdrawal in the prominence of the automobility system, their analysis is primarily technical in nature and focuses on issues such as fuel availability and propulsion system performance. Although these issues are of clear importance, they cover only one dimension of the ways in which the automobility system may change in the coming decades. With significant innovations in the communication technologies embedded within cars and the way cars are accessed being anticipated in the near future, visioning activities will need to start considering these issues simultaneously rather than in isolation if they are to be accurate in their depiction. To this end, this paper seeks to take a more integrated approach by assessing stakeholder perspectives of the future of automobility which is not constrained to a specific technical or social innovation.

\subsection{Transitions in Automobility}

Socio-technical investigations of system transitions have explored the manner in which a sustainable future for the automobility system may be realised. Offering initial guidance in this area, Schot et al. (1994) outline a quasi-evolutionary model to describe the processes through which new technologies emerge and integrate with society. This model positions the variations of technical development and selections of the market environment as being partly independent yet inherently coupled components. This coupling is apparent in three different mechanisms covering the technological forcing of 
innovation towards desired objectives, the application of strategic niche market experiments to direct the staged introduction of new technologies and the creation of new market alliances of transition agents in a technology nexus. Concentrating on the development of niche markets, Nykvist and Whitmarsh (2008) outline how a group of niche activities comprising of radical changes in technology, shifts from providing products to services and the expansion of demand management policies can comprise an area of innovation in the sustainable mobility system. Geels (2012) incorporates a number of these mechanisms and activities into his multi-level perspective (MLP) on transitions in low-carbon mobility and discusses how the existing system landscape may change due to the effects of destabilising forces inclusive of public concerns regarding climate change, the peaking of global oil production and the rapid diffusion of ICT. However, stabilising forces, associated with cultural preferences and values, characteristics of the built environment and an expansion of the networked society, may result in the persistence of the existing system.

With the automobility system representing an area which is actively managed by local, national and super national governments, the potential exists for government agencies to steer the transition in this system's configuration onto a trajectory which is compatible with their visions of the future. Smith et al. (2005) describe the governance of transitions through both the coordination of effort and the ability of governments to influence market selection pressures and the adaptive capacities which are available to facilitate system transformation. The opportunities for governance to facilitate transitions is further defined by Loorbach (2010) in his transition management framework which distinguishes different categories of activities which operate across different time horizons that governments can pursue to steer transitions. These include strategic actions aimed at influencing long-term cultural issues (e.g. the place of the car in society), tactical actions which attempt to alter the socio-technical structures which support the existing system (e.g. car insurance procedures and vehicle regulations) and operational activities that focus on projects and programs intended to promote innovation (e.g. trials of alternative propulsion systems).

The research presented in this paper does not directly apply the MLP or transition management framework to conceptualise how a sustainable future for the automobility system may emerge. However, the outcomes of the analysis are broadly compatible with a number of the issues contained within these conceptions and transition studies more generally. For instance, the perspectives assessed in this study generate insights regarding how technical innovations may combine with the increasing social desire for flexible access to mobility services to destabilise the current system configuration. These perspectives also offer views concerning the self defence mechanisms which the 
current system deploys to sustain its dominance. These narratives of expertise may also provide guidance concerning the types of policy which governments can take in order to steer the transition towards a desired outcome.

\section{Methods}

\subsection{Data Collection}

The collection of data took place at a colloquium organised by the authors in the UK during the summer of 2014. The primary purpose of the event was to bring together transport professionals who were interested in discussing the future of automobility in British society to share their experiences and opinions. This event was advertised through various research and professional networks and was open to any interested party to attend, meaning that the structure of participants was self-selected rather than pre-arranged. The event consisted of morning lectures covering political, business and sustainability perspectives on automobility with a series of focus groups scheduled for the afternoon. These focus groups occurred under the Chatham House Rule and considered different aspects of the future of automobility. A total of 25 transport professionals participated in the event including representatives from academia $(n=13)$, business $(n=5)$ and non-governmental organisations $(n=7)$. The composition of the participants covered professionals with varying degrees of experience in the transport and mobility field including early to mid career researchers and professionals with established track records. All participants were UK-based, though geographically spread, and few participants knew each other previously. Although formally invited, no representative for the mainstream automotive manufacturers or the UK Government participated in the event, meaning their views are absent from the research.

Due to the presence of a diverse group of transport professionals, it was agreed by the authors that the most efficient method of gathering experiences and opinions would be through carefully designed focus groups. The use of focus groups is widespread in the social sciences and, in the conduct of foresight studies, is a method which is growing in prominence in the field of transport and mobility research (Hickman and Bannister, 2007; Lucas and Jones, 2009; Lyons and Goodwin, 2014). Focus groups were favoured as, unlike interviews, they can foster an interactive dialogue between participants, allowing for views to be expressed, evaluated and refined in a collaborative manner. This approach allows for the social context of automobility to be present within the discussion, generating multiple perspectives on the topic as opposed to an individualistic view. 
Six one-hour focus groups were held across two parallel sessions (i.e. two batches of three focus groups). The three focus groups which took place during the first parallel session concentrated on transitions in automobility and the implications this may have for society, with the focus of the three groups on: a) sustainability; b) technical; and c) policy issues. The focus groups in the second parallel session were orientated around the roles and responsibilities of different agents that will be involved in a transition, from the point of view of: e) individuals; f) government; and g) manufacturers or developers.

Table 1: Overview of prompts used during the focus groups with specific focus delineated by the [1], [2] and [3] markers

\section{Parallel Session One}

- What are the key challenges in developing a ([1] sustainable, [2] technical, [3] policy) transition in automobility?

- Identify the important enablers and inhibitors that will facilitate or restrict a ([1] sustainable, [2] technical, [3] policy) transition

- What are the key time horizons which are pressing in this area?

- How does the theme of ([1] sustainability, [2] technical, [3] policy) connect to the other focus group themes?

\section{Parallel Session Two}

- What sustainability issues which arise from automobility (current and future) can be addressed by ([1] individuals, [2] governments and [3] manufacturers)?

- What conflicts may arise between the needs of different social groups?

- What value does the car have in individual autonomy?

- How can issues of cultural and infrastructural lock-in to automobility be overcome by ([1] individuals, [2] governments and [3] manufacturers)?

- Does the car have a future in British society?

Participants were advised to select the focus groups which they felt they could contribute the most to, with a relatively even split in participants generated. Each of the focus groups was facilitated by a member of the project team who had been involved in the development of the focus group structure. A prompt sheet (reported in Table 1) was developed to be used by the focus group facilitators in order to promote discussion. This prompt sheet contains a series of points linked to the future of the automobility system, covering such issues as challenges, pathways, tradeoffs and responsibilities. In addition to the prompt sheet, the facilitator attempted to steer discussion to remain regarding professional expertise rather than personal opinion. However, as may be expected in such an inherent subject as automobility, where all participants are also part of the automobility system to some degree 
as well as professionals within it, it was difficult to ensure separation between professional and personal experience.

\subsection{Analysis}

The dialogue in each of the six focus groups was recorded and then transcribed verbatim by a single member of the project team in an effort to improve the reliability of the transcription process. Once the written evidence from the focus groups had been produced, a multi-stage thematic analysis of the text, which is summarised in Figure 1, took place based on a standard inductive approach (Guest et al. 2012) and expanded upon by the authors in an iterative process of reflection. The analysis focused on the content of the transcript with other aspects of the focus groups such as speech patterns and participant dynamics not being explicitly evaluated.

\section{Stage One: Open coding of the transcripts}

Two members of the project team were designated as initial-coders and were each assigned three of the focus group transcripts. These transcripts were then coded in an open manner in order to categorise parts of the text around common points of discussion.

\footnotetext{
Stage Two: Development of the thematic framework

The open coding categories developed in stage one were compared between the initial-coders in order to determine the degree of similarity and divergence. From this comparison, a thematic framework was developed which unified the common aspects of the open coding.
}

\section{Stage Three: Refinement of the thematic framework}

Each transcript was blind coded by the initial-coders using the thematic framework developed in stage two. The coding was then compared to identify areas where the same and different codes had been assigned to the text. Where different codes were assigned, the initial-coders deliberated in order to decide on a mutually acceptable code.

\section{Stage Four: Validation of the thematic framework}

The thematic framework was presented to the remaining project members for critical appraisal. Following this evaluation, a number of minor changes in the structure of the thematic framework were enacted with transcript coding being reassigned where necessary.

\section{Stage Five: Presentation of the common narrative}

The finalised thematic framework was inspected by all members of the project team in order to highlight text that captures key issues related to the specific themes.

Figure 1: Overview of the stages progressed through in the analysis of the focus group transcripts 


\section{Findings}

The richness of the focus group narratives allows for the construction of a countless array of potential coding structures which combine discussion points in different categories and sequences. The selection of the coding structure presented in this paper was based on a number of considerations. Firstly, a structure which is accessible was deemed preferable, to assist interested readers in understanding the information that it contains. Secondly, a structure which offers insights which are directly applicable to facilitating system progression towards a more sustainable state was considered desirable as this will likely generate the most impact from the work. To this end, the analysis primarily focuses on what is articulated by the participants rather than attempting to identify hidden meanings or unspoken issues and thus represents a surface based analysis.

After due deliberation, it became apparent that the codes being formatted during the analysis could be categorised into three themes. These cover the evolution of the automobility system (Section 4.1), the perceived barriers to progress for the system (Section 4.2) and the potential mechanisms through which a transition might be achieved (Section 4.3). An overview of these themes and their sub-codes is presented in Table 2 with a more thorough description with supporting comments is provided in the following sections.

Table 2: Overview of thematic framework stating the primary themes, theme descriptions and codes associated with themes

\begin{tabular}{|c|c|c|}
\hline Theme & Theme Description & Theme Codes \\
\hline $\begin{array}{l}\text { System } \\
\text { Evolution }\end{array}$ & $\begin{array}{l}\text { The automobility system has continuously evolved } \\
\text { throughout its history. Significant problems } \\
\text { currently exist which have the potential to be } \\
\text { addressed by a transition towards sustainability. }\end{array}$ & $\begin{array}{l}\text { Past Experience } \\
\text { Current Conditions } \\
\text { Future Vision }\end{array}$ \\
\hline Barriers & $\begin{array}{l}\text { The realisation of a sustainable transition will likely } \\
\text { be hindered by a host of interlinked obstructions } \\
\text { which promote the status-quo and restrict decision } \\
\text { making. }\end{array}$ & $\begin{array}{l}\text { Acceptance } \\
\text { Systemic } \\
\text { Governance } \\
\text { Decision Making }\end{array}$ \\
\hline $\begin{array}{l}\text { Transition } \\
\text { Mechanisms }\end{array}$ & $\begin{array}{l}\text { A number of possible strategies might be pursued to } \\
\text { promote the shift towards a sustainable trajectory } \\
\text { for the system. }\end{array}$ & $\begin{array}{l}\text { Government Policy } \\
\text { Business Innovation } \\
\text { Citizen Agency }\end{array}$ \\
\hline
\end{tabular}




\subsection{System Evolution}

Discussions on the future of the automobility system in the focus groups described how it has been shaped into its current form and what insights this could provide for the future. In turn, three key subthemes were apparent relating to past experience, current conditions and future vision.

\section{Past Experience}

From a casual glance at the UK statistics on the historical expansion of car use (Department for Transport, 2014) it can be tempting to categorise the automobility system as one which displays the incremental change of a matured market. These statistics mask the varied dynamics of the system which has witnessed significant alterations in the technical, social and policy settings. These dynamic aspects of the automobility system were discussed by participants, who described the manner in which new technologies have been introduced into the system and the consequences that have been experienced. These consequences often reflect negative impacts not originally conceived during technology development (Hubers and Lyons, 2013). For example, one participant concentrated on the widespread diffusion of satellite navigation expressing:

A very historical example would be in car navigation systems where there is the issue that they will direct drivers down routes which might be practical, but may effectively be encouraging rat-running. [Academic participant - Policy focus group]

The unintended consequence here is technically optimal routes becoming short-cuts (known colloquially as rat-runs), resulting in a trade-off between individual benefits (i.e. shorter travel times) and collective costs (i.e. disturbance of residential neighbourhoods). Similar examples of unintended consequences can also be observed in the propulsion technologies and fuels that have been introduced without consideration of how they may disrupt wider systems. An example was given of the introduction of biofuels into the transport sector with one participant stating a view that "policy [was] running well ahead of the technology and we didn't correctly understand the influence of indirect landuse change" [NGO participant - Policy focus group].

In other words, reflecting that the eagerness to pursue first generation biofuels for their direct environmental benefits meant that other issues were overlooked. This may be endemic of a wider issue in science, engineering and technology, that practitioners do not see such concerns as being within their remit (Royal Academy of Engineering 2011; Vermaas et al. 2011). These two examples 
highlight the issues that can occur when the pace of technical innovation, the understanding regarding the direct and indirect impacts of the innovation and its policy management are not synchronised.

\section{Current Conditions}

Acknowledging that the system has the capacity to change likely represents the first step in considering what future states of the system may involve. These future states were put into context by the participants through a description of the system's current condition. The embedded nature of the system was outlined in terms of the car's ability to provide its owner with a personalised environment that allows the driver a greater degree of control over the space which they inhabit. This allowance of personalised space was described by one participant as: "a modern car insulates you ... it is so reliable, so easy, that it cocoons you as a technology and protects you from the outside world. [Business participant-Technical focus group]. This concept of insulation holds parallels with the view of the car as a refuge (Featherstone, 2004), as a place of dwelling (Kent, 2015) and as a tool of secession from public space (Henderson, 2006; Mattioli, 2014). Indeed, the participant goes on to suggest that insulation operates on a number of different levels, both in the car's ability to protect the driver from the natural and human environment:

In a contemporary world, it is actually quite difficult to isolate yourself in your own little space, and a car gives you that. [Business participant - Technical focus group]

British society has seemingly become normalised to what Dant (2004) describes as the affordances which cars provide, a view also taken by Rajan (2007, p. 89), who further suggests this "conditions us to accept its importance without question". The dominant position of the car over mobility patterns in the UK has contributed to the development of related systems which seemingly cater towards car ownership. One participant described this issue through the interactions between car-based mobility and shopping practices, noting that "people doing their weekly shop, it seems as if they are tied to the supermarket with its huge free parking" [Business participant - Sustainability focus group]. Another participant felt that the assumption of car ownership extended beyond the private economy and was also affecting the provision of public services which have undergone a period of spatial centralisation, stating that "centralise and you save money as an institution; we as a society bear the extra cost of having to travel to that place" [Academic participant - Technical focus group]. These processes can hold significant implications for society. Firstly, they assist in sustaining the automobility system by increasing the accessibility gains associated with car ownership and use and fuelling a self-reinforcing dynamic of increasing car dependence (Dupuy, 1999). Secondly, they have the effect of marginalising 
groups of citizens who cannot attain access to the system, thus limiting their participation within society (Social Exclusion Unit, 2003).

\section{Future Vision}

There appeared to be a general view among the participants that the system is entering a phase of flux which has the opportunity to alter the manner in which society utilises car-based mobility. While the academic literature on this topic highlights structural (e.g. economic downturn, demographic changes) and technical (e.g. propulsion system innovation) factors likely to promote change, the comments of focus group participants centred mostly on the importance of cultural-psychological factors (e.g. changing norms and values). In this context, reference was often made to recent trends concerning reductions in car travel and car driving license attainment in young adults observed across different economically developed nations (Kuhnimhof et al, 2012; Hopkins, 2016b). One participant expressed a view that opinions towards cars among young adults appear to be shifting, with less social requirement seemingly being placed on car ownership:

Something is happening in terms of what status is being attached to cars potentially in the younger generations. [Academic participant - Sustainability focus group]

The ritual of passing the driving test and purchasing the first car is being superseded by the increasing importance placed on participation in the networked society. The participant goes on to mention that "There is some hypothesis that younger people would prefer to be on the move and networked up ... than drive and not be able to" [Academic participant - Sustainability focus group]. In parallel to these changes in the social position of the car among some cohorts of society, participants made reference to a series of technical innovations which are or will soon be introduced into the automotive sector. This is most apparent through the entry of Electric Vehicles (EVs) which embody a number of distinct characteristics (e.g. as the ability for decentralised refuelling and reduced vehicle operating costs). One participant expressed a view that different innovations in propulsion technology open up new possible blends in the composition of household vehicle fleets, similar to the Hybrid Household hypothesis proposed by Kurani et al. (1996):

I can see a situation where [citizens] who run two cars at the moment, one could be hybrid and one could be an Electric Vehicle. That would serve their needs and be a massive step forward without compromising their mobility. [NGO participant - Sustainability focus group] 
Concentrating on the prominence of EVs in the current transport discourse, a view was voiced that the widespread adoption of EVs will produce a different set of behaviours and preferences. One participant noted that "mainstream electric car drivers, are a different breed of person, they are driving for a different reason, with a different set of behaviours" [Academic participant - Technical focus group]. This statement suggests that the introduction of these new technologies into the automobility system has the potential to alter citizen's perceptions of what cars are for, shifting what Dant (2004) describes as the meanings which surround the social entity of the Driver-Car. Taken in another way, the views of this participant may indicate that new spaces are beginning to open, allowing the automobility system to evolve to exploit the new possibilities which are available, linked to Goldman and Gorham's (2006) concept of New Mobility. Participants expressed the view that a more significant shift in the system could be realised through the combination of technology which automates the process of driving with business models that are orientated around the shared ownership of cars (referred to as product service packages):

Providing a product service package ... that does take you into a very different world ... you could actually offer more mobility to more people with fewer cars so you would get a winwin. [Business participant - Technical focus group]

Such a view features in Kent and Dowling's (2013) description of the emergence of carsharing practices, who note the possibilities which exist to utilise car-clubs as a stage through which to introduce new clean propulsion technologies. This approach positions car-clubs as a conduit for the application of strategic niche management (Schot et al. 1994; Schot and Geels, 2008), which would allow multiple innovations (i.e., flexible car access business models and advanced propulsion system vehicles) to be evaluated simultaneously in a controlled environment rather than in isolation. Taking Kent and Dowling's (ibid.) view a step further, it is at this intersection between new propulsion technology, vehicle automation and shared ownership where the possibility for transformational change in the automobility system is greatest.

\subsection{Barriers}

During the course of the focus groups, participants expressed views relating to a wide spectrum of different issues which may restrict the progression towards a more sustainable state for the automobility system, holding similarities with what Geels (2012) refers to as stabilising forces. Here, four related sub-themes were identified being acceptance, systemic, governance and decision making. 


\section{Acceptance}

The embedded nature of the existing automobility system in the practices of everyday life generates a situation whereby individuals and institutions operating in the system actively resist potential changes in the system structure that they have become normalised to. One participant noted that this resistance to change can be seen to manifest in the general desire of drivers to inhabit a private space, stating that "If it is your own car, you can really make it your own space. These shared use cars ... you can't leave your toast crumbs on the floor or your own music in the CD" [Business participant - Technical focus group]. This personalisation of the car seems to surpass a desire to dwell within a customized environment to a deeper harmonisation between driver and car (Wong and Ahuvia, 1998; Dittmar, 1992), whereby the car combines with the personality of the driver to create a sense of joint identity:

You have your own car as an extension of yourself. Or, you could use a Car Club car, still have your personal space ... but it is not an extension of self. [Academic participant - Technical focus group]

Participants raised concerns surrounding how the new innovations entering the automobility system will fit into this existing structure of practice and meaning. There is potent imagery surrounding what car ownership represents and a deep rooted sense of connection between drivers and their cars which assists in generating a situation whereby:

Most people see having a car as a human right and a lot of people wouldn't give it up for anything. [Academic participant - Citizen focus group]

This issue of acceptability seemingly acts as a filter on what can and cannot be discussed when considering the automobility system. Certain topics which might be viewed as restrictive to the status quo of automobility, such as limiting car use, are often taboo, with the proponents of such topics being critiqued and marginalised in public discourse (Gössling and Cohen, 2014). A participant eluded to this issue by stating "persuad[ing] people to travel far less ...that is always the big thing, that is the one thing that we know we'd do but, you know, you just can't do that" [Academic participant Sustainability focus group]. This filtering constrains the way in which the system is governed with one participant noting "ministers are very concerned about not wanting to be anti-car" [Academic participant - Governance focus group]. This position assists in understanding the current preference in UK government policy towards incentivising car alternatives as opposed to de-incentivising car use 
(Wright and Egan, 2000; Mullen and Marsden, 2016), a point articulated by Banister (2008) in his statement that "public acceptability drives political acceptability" (p.76).

\section{Systemic}

The co-evolution of the automobility system with other institutions and infrastructures has generated a situation of interdependence, whereby car ownership is perceived as an essential requirement necessary to facilitate everyday lifestyles (Urry, 2004; Pooley, 2016). Participants expressed their views on several lock-ins to the current structure and configuration of the automobility and ancillary social systems which involve the legacy of past decisions restricting the opportunities for transitions. For instance, the substantial luggage capacity of conventional cars has assisted in establishing the practice of bulk shopping with citizens becoming accustomed to the ability to transport goods back to their households which would be challenging to do without car access (Hubers and Lyons, 2013; Mattioli et al. 2016). In other words, the prevailing ways in which shopping practices are conducted has come to depend on the availability of the car (RAC Foundation, 2006). This point was raised by one participant who referred to existing research which indicates that "just carrying the shopping home, one bag of shopping, just two kilograms, that is enough to slow you down" [Academic participant - Sustainability focus group].

It was felt that the shopping habits of car-owning citizens have a significant influence when evaluating car purchasing options, with one participant stating that "the size of the boot ranks much higher as a consideration than environmental issues and often nearer the purchase price" [Academic participant Sustainability focus group]. Indeed, the concept of the car as an instrument which has become intertwined with a substantial proportion of modern life was raised by another participant who expressed a view that we have "entered a paradigm of escortism" [Academic participant - Individual focus group]. This statement appears to be connected with the gradual enlargement of household activity spaces leading to an expansion in escort trips by 17\% in the UK between 1995 and 2013 (Department for Transport, 2015). One participant appeared resigned to the view that attempts to address these issues of car dependence are likely to prove challenging:

This idea that we are going to build in flexibility, we are going to change behaviour, I think it is something that is very very difficult to do in human society. [Academic participant-Technical FG] 


\section{Governance}

The existing governance apparatus of the automobility system represented a repeated topic of discussion amongst participants who reflected on the role of government in directing system developments. One participant detailed their view of how a conservative perspective seems to be inhibiting more innovative ideas:

You have a bell-curve of innovation and all of the interesting bits are around the edges [but] all of the calls are defined by the incumbent mindset ... all of the possibilities out there [on the edges], [policy makers] honestly cannot see as possibilities. [Business participant - Policy focus group]

This opinion appears to convey the message that there is a distinct status-quo bias in effect which favours incremental alterations to the existing governance apparatus whilst marginalising what might be perceived as creative thinking. Status-quo biases of this nature hold parallels with the concept of technological paradigms set out by Dosi (1992) whereby the perspectives of organisations are focused on precise issues which are present within the existing technical regime and are thus blind to more creative opportunities which exist generating what Kemp et al. (1998) refer to as an exclusion effect. This stance is supported by the opinion of one participant who mentioned:

In transport there is this big idea that we moved away from predict and provide policy towards a more demand management world. It never really quite happened and, the way I see policy happening is exactly the same as ever, predict and provide. [Academic participant Sustainability focus group]

\section{Decision Making}

The desire for evidence-based policy making in public administration generates a situation whereby civil servants strive for certainty (Sanderson, 2002). This is visible in the degree of public scrutiny associated with policy deployment in the transport sector, which likely stems from for the direct implications citizens feel exist between transport policy and their everyday lives. During the course of the focus groups, participants outlined three key areas which were felt to be restricting the ability of the governance system to make decisions while considering the automobility system covering the complexity of decision making, the availability of information, and the manipulative behaviour of certain system agents. These three key areas are discussed in turn. 
Firstly, the issue of inherent complexity in the decision making process was discussed repeatedly. The automobility system is distinctly vast in both its scale and scope, which in part assists in producing the diverse range of barriers which restrict system progression. Indeed, attempting to consider the system in its entirety can prove to be challenging, as summarised by one participant who noted "to actually sit back and say - okay, how do I make sense out of all of this? It is actually quite hard" [Academic participant - Policy focus group]. The difficulty in considering the automobility system holistically leads to a situation whereby research and practice tends to favour a reductionist approach by which selected system elements are examined in isolation (O'Sullivan, 2004). Whilst research that pursues this strategy allows for a deeper appreciation of the specific issue under investigation, it might struggle to understand how the specific issue integrates with the wider system. One participant elucidated this subject by stating that "[transitions] do come along quite regularly, but ... they always take you by surprise and ... they are always quite explicable in the benefit of hindsight. Maybe we have got to get better at identifying them with foresight" [Business participant - Policy focus group].

The preference to favour focused studies which concentrate on specific issues might be in part motivated by the challenge of delineating the boundaries of the automobility system, which are porous and overlap with other aspects of society. This inherent complexity of system structure is highlighted by one participant who noted the difficulties in understanding citizen behaviour:

You can put all of your numbers into a model but we are all different, we are all wired up different, and it can contradict rationality. [Academic participant - Sustainability focus group]

Secondly, access to relevant information and quality data was also highlighted as a common barrier in the decision making process. The process of decision making is intrinsically linked to the information which is available. In such a widely researched field as automobility, the availability of information is not normally an issue. The problem often lies in the quality of the information, with one participant noting that obtaining information from reliable sources can be a significant challenge:

The problem is the [European] commission and the UK government really struggle to find good sources of independent evidence. The reality is, on a lot of issues, there is no good source of independent evidence. [NGO participant - Policy focus group]

This difficulty in sourcing high quality information may in part stem from the substantial quantity of information now available. Indeed, this large base of information generates a situation where 
information can seem mutually exclusive, with different information sources portraying incompatible positions:

Policy makers find it quite challenging to find the truth in this area. Because they are probably always getting mixed messages on different aspects. [Academic participant - Policy focus group]

The conflicting nature of some information sources makes decision making a more challenging task as the acceptance of one position may lead to the rejection of another. Deciding which information source is the most reliable and valid appears to be no easy feat and introduces a significant degree of uncertainty as noted by one participant "Policy makers struggle in this area of technology and transport because there is so much uncertainty. They do receive very conflicting views on essentially key points of detail" [NGO participant - Policy focus group].

These issues surrounding the quality of information are not restricted to their effect over the processes of governance but also extend to other system stakeholders. The growing research base surrounding the topic of behaviour change in transport demonstrates that citizen action will be an important component of any sustainable transition (Whitmarsh et al. 2009). The desire to empower citizens in this area has the concept of information provision at its core. If citizens are uncertain regarding the validity of the information they are receiving, this has the potential to harm confidence as noted by one participant "[the unreliability of information] has damaged the consumer trust in the information that they get" [Academic participant - Sustainability focus group].

Finally, the private-sector firms currently engaged in the production of vehicles represent one of the largest sources of information for the system, notably on environmental performance of vehicles, granting these firms a position of influence over system developments. Participants in the focus groups repeatedly raised concerns regarding the actions of private-sector firms in this area, who are seen as steering system developments towards their own vested interests (Vergregt and Brown (2007). For example, one participant raised the concept of misdirection, suggesting that private sector firms are employing deliberate strategies to slow down progress with "[automotive manufacturers] sticking their hand up and saying - the awful thing is we don't know what is going to happen, which way it is all going to go, we cannot afford to fund research programmes in all of these things" [Business participant - Policy focus group]. 
This concept of misdirection was stretched by another participant who suggested that certain actors are directly manipulating the governance apparatus in an effort to attain their own desired outcomes, "policy is a very frothy forum, where ideas about technology can be injected quite quickly and players can manipulate the policy process relatively easily" [Academic participant - Policy focus group]. A visible expression of this issue of manipulation was felt to be present surrounding car efficiency and emissions testing in the European Union. The current testing procedure (the New European Driving Cycle) was thought to be no longer fit-for-purpose due to ingenuity of the private-sector firms in identifying weaknesses in the procedure:

The Euro [emission] standards for vehicles have abjectly failed. Why have they abjectly failed? Because the car companies have found ways they can achieve those standards in tests, not on the roads. [NGO participant - Policy focus group]

These weaknesses in the existing test are well documented (Silegham et al. 2014) and have risen to the attention of the general public with the recent announcement of certain diesel vehicles violating the protocols of the Clean Air Act in the United States of America (Environmental Protection Agency, 2015). The parameters of the test are also not particularly suited to the innovations in propulsion technology which have come online since the test was introduced in 1997. Indeed, the European Commission Joint Research Centre has ongoing research to develop new drive cycles that could better represent real world driving conditions and new propulsion technologies (Fontaras et al. 2014). Participants however suggested that the development of a new test was being delayed to allow for extensive negotiations to take place:

[New regulations] will be fought tooth and nail by the lobbyists and the threshold which is agreed will be not nearly as aggressive as it should be because nobody else has got the firepower of those lobbyists to keep the threshold up. [Business participant - Manufacturers focus group]

This type of activity holds parallels to the political strategies employed by automotive manufacturers in the United States, with Wesseling et al. (2015) noting a preference for defensive tactics in an effort to oppose policy intervention in the California Zero Emission Vehicle mandate. A similar perspective on this issue is offered by Dudley and Chateerjee (2012), who argue that the powerful assets which are at the command of the existing car regime allow it to dominate discussions regarding system developments. Indeed, Douglas et al. (2011) go one step further in comparing the activities of car 
manufacturers to the strategies deployed by the tobacco lobby, which systematically attempted to discredit scientific research pertaining to the harmful effects of smoking.

\subsection{Transition Mechanisms}

In order to approach the barriers outlined, a host of different proposals were put forward in the focus groups describing the ways in which system progression could be realised and which actors may be responsible. The Transition Mechanisms theme groups codes which cover some of these proposals, including government policy, business innovation, and citizen agency.

\section{Government Policy}

Political governance was generally viewed by participants as having a guiding role to play in setting the rules which regulate system activity. This view shares parallels with the growing literature on transition governance (Smith et al. 2005; Loorback, 2010; Frantzeskaki et al. 2012), that acknowledges the importance of political agency and how the expression of the authority held by government can generate appreciable differences to the transition process. Participants noted that a certain degree of leadership is necessary in order to promote transformational change and outlined a number of examples of situations in which political will has been instrumental in achieving substantial progress in the transport system. Specific mention was made to the perceived need to reduce the friction that exists between the objectives of society and the objectives of business:

We have got to get industry aligned with the objectives we are after if we have got any hope. [Business participant - Policy focus group]

Other participants put forward specific proposals to achieve this alignment. These covered the application of market intervention in the form of cap-and-trade policies to restrict emissions levels, with one participant questioning "should we all have a carbon allowance and spend the way we want?" [Academic participant - Technical focus group]. The idea of personal carbon allowances, which is being increasingly explored in transport literature in terms of how information concerning allowances and carbon footprints are conveyed (Waygood and Avineri, 2012), seemed to have some traction between different participants, with one participant mentioning that policies of this manner have the potential to lock-in a sustainable trajectory. However, agreement on this issue was not universal, with another participant raising concerns relating to the ethical implications of economic policies: 
I think better not to do it through redistribution, because then the richest can carry on doing it. It is better to do it through regulation, when it is poisonous. [Business participant - Governance focus group]

These proposals illustrate a separation that seems to exist between enacting policy which is focused on changing behaviour and policy which concentrates on altering the technical specifications of vehicles. These two categories of policy tend to be introduced in isolation and not considered in an integrated manner as components of a policy mix. One participant gave voice to this issue by calling for more experimentation in policy making to try different alternatives and combinations in order to evaluate what works:

We are on the verge in Europe of trying with green targets and actually playing with the instruments which are available ... but we haven't quite ticked it yet [Academic participant Policy focus group]

\section{Business Innovation}

The discussions which took place during the focus groups tended to position the private-sector as the primary source of technical innovation in the system. One participant noted that "one thing this industry has been incredibly good at is driving down the unit cost of cars whilst the quality adjusted content has gone up massively" [Business participant - Manufacturers focus group].

Proposals put forward during the focus groups tended to fall into two categories associated with organisational innovation. The first of these categories gravitated around the idea of developing strategic niches in which to introduce innovations and allow them to mature. The idea of establishing protected spaces for new technologies to develop in before being exposed to the commercial pressures of the mainstream market is a well understood strategy in technology studies (Caniëls and Romijn, 2008). The deployment of EVs was singled out as an issue of discussion with participants describing how they could be introduced into commercial fleets:

Taxis are heavily regulated now and if they had to be electric, the degree of exposure it would be ... [Academic participant - Sustainability focus group]

Opportunities for EVs to be adopted by commercial fleets (or in otherwise niche markets) were not felt to be limited to taxi services, with one participant mentioning an array of different operations 
where EVs might be suitable such as "light-goods vehicle deliveries, pizza persons ... electric Post Office vans ... and they will tell their neighbours about what it is like to drive an electric vehicle" [Academic participant - Sustainability focus group]. The notion of visibility was further discussed in terms of raising awareness regarding the changes in the automobility system amongst citizens "It is the experience and the exposure which is key to getting people used to electric mobility" [Academic participant Sustainability focus group].

The second category grouped proposals that discussed the potential for significant shifts in the manner in which the system of automobility is accessed. Participants made reference to the movement towards flexible models of vehicle use and the potential benefits this may produce:

If you sell a service, your interests are, instead of obsolescence and high running costs, your interests are longevity and low running costs. [Business participant - Manufacturers focus group]

The potential benefits outlined seemed to cover both improvements to the environmental sustainability of the system but also the opportunity to improve system access to those who are currently excluded or forced into car ownership. This point was raised by one participant who mentioned that a shift towards flexible vehicle access models may expand system participation:

The consumer at that point is no longer simply purchasing a car but they are trying to purchase mobility and, at that level, you could actually offer more mobility to more people with fewer cars so you get a win-win. [Business participant - Technical focus group]

\section{Citizen Agency}

The topic of raising awareness was particularly salient throughout the focus groups. Participants expressed views that some of the issues linked to automobility lacked visibility with the general populace and that impact could be attained by framing the issues in alternative ways:

There are millions of people living in London who could take the view that they are being poisoned and their quality of life is being reduced. [Academic participant - Governance focus group] 
This proposal re-frames the current narrative around the antagonisms of car use to position air quality as a prominent issue. With citizens having a tendency to express a psychological distance to the concepts of climate change, impacting on willingness to act in order to address this issue (Spence et al. 2012), discussing the need to alter the automobility system from an air quality perspective may generate more traction. Whilst attempting to empower citizens by demonstrating how individual action can produce tangible outcomes can be a rewarding strategy (Whitmarsh et al. 2009), participants seemed to favour a socially orientated approach to re-framing the issue, focused on shifting social norms around what is deemed to be acceptable behaviour, with one participant noting social norms can act as "a significant potential leaver to enact change in behaviours and attitudes, to equate the high consumption of resources with anti-social behaviour" [Business participant - Technical focus group]. The proposal to influence social norms surrounding an issue of everyday lifestyle can appear to be a significant challenge, with no clearly defined procedure on how to achieve change. In an effort to demonstrate how shifts of this nature have been achieved in other areas, participants referred to the success of the 2007 UK smoking ban in altering the way citizens perceive smoking in enclosed public places:

The way we have moved towards segregated smoking and the design of the cigarette package ... couldn't you use the same method on the car ... it would be something which is quite visible and says how much carbon you are producing. [Business participant - Sustainability focus group]

\section{Discussion and Conclusions}

This paper presents an outline of the perspectives of transport professionals concerning the future of the automobility system and the possibility of a shift towards sustainability. The analysis of the focus group transcripts has identified three common themes encompassing System Evolution, Barriers, and Transition Mechanisms. These may not seem to be revolutionary, but they set out a concise description of how automobility is currently perceived by its operatives, whom as individuals have a role to play in the system's future. The common narratives share overlaps with the prompt-sheets utilised to frame the focus groups. Although we recognise that this similarity could be explained by the format of the focus groups or the pre-conceived notions of the authors, this does not rule out the prevalence of these subjects within the dialogue nor make them less noteworthy, and indeed it is the identified subthemes that are perhaps of most interest here. 
One way of interpreting the findings could be to see the statements of transport professionals as mere reflections of the current hegemonic discourses around the automobility system, that is, conscious rationalisations of automobile practices shaped by policy and academic discourses, expressing the deep social incorporation of automobility (Freudendal-Pedersen, 2007) and strongly held taboos in transport policy-making (Gössling and Cohen, 2014). Indeed, while the focus group participants are keen to point out the status-quo bias of governance institutions (Section 4.2), one could argue that some of their views reveal a similar bias. This is exemplified among others by their tendency to reify current social practices (e.g. car dependent weekly bulk-shopping) and preferences (e.g. the private space of the car).

On the other hand, it would be wrong to conclude from our findings that a conservative perspective is predominant among our focus group participants. In fact, the discussions also reveal a willingness to endorse radical policy measures such as personal carbon allowances and campaigns aimed at shifting social norms surrounding car use (Section 4.3) and the participants appear keenly aware of the role of vested interests in stalling technical and governance innovations. Overall, our findings reveal a mixed picture; while some of the common discourses identified contribute to reproduce the automobility system in its current form, others suggest that radical stances are not uncommon among British transport professionals. A contribution of this work is to bring to light the coexistence of different perspectives on the future of automobility.

Our findings reveal a degree of agreement on the view that a window of opportunity is emerging for the automobility system to shift onto a sustainable trajectory due to the entry of technical innovations into the car market and shifts towards new forms of car access. Indeed, it is the potential alignment between these different issues where the transformational potential in this system is greatest. Yet, attempting to consider how these different issues will combine together is inherently challenging, with a large degree of alternative combinations being possible, which makes it difficult to envisage the future of the automobility system with any great degree of accuracy. This complexity generates significant barriers to progression, both in terms of generating accurate information concerning the outcomes and implications of these different innovations. This restricts, for example, the ability to make effective decisions given the large degree of uncertainty concerning how the system may restructure and gaining support for these different innovations across system agents.

In part, these challenges also extend to how the introduction of new technologies and alterations in social desires in the automobility system are being considered in research, with there being a tendency 
to examine these issues in isolation. Whilst focused approaches provided detailed insights concerning such issues as citizen reaction to innovations (Caperello and Kurani, 2012; Egbue and Long, 2012; Graham-Rowe et al. 2012) and innovation barriers (Steinhilber et al. 2013), they provide little knowledge regarding how different innovations will coalesce or repel and any tradeoffs which may exist. Part of this focused approach likely stems from the inherent challenge of designing projects which examine a combination of complex innovations simultaneously. However, as the automobility system begins to assemble multiple socio-technical innovations, taking a pluralistic approach will likely represent a requirement to effectively conceptualising system change.

In closing, this paper returns to the concept of automobility with which it started. Automobility is being able to self-govern one's physical movement in order to achieve accessibility to things necessary to achieve a desired quality of life. To date, this has been chiefly associated with car ownership, though this is only one means through which automobility can be. With the current automobility system potentially entering a stage of flux, now is an appropriate juncture to question if the owner-driver car is still a suitable basis for automobility, and what role automobility may have in a sustainable future. To answer this, we need to understand what the car means to society, and what feasible alternatives exist. Furthermore, how can new technologies, social structures and governance or business models be embraced in order to move automobility forward within a sustainable agenda that may be in conflict with the current system. This paper has taken a step along this path, by presenting views on the automobility system that are shared by British transport professionals, which may aid in framing these important questions.

\section{Directions for Future Research}

This paper has taken a snap shot of the way transport professionals are currently talking and thinking about the place of the car in the future, offering a candid appraisal of how these issues are discussed in these circles. There are of course alternatives to the approach taken here. Other stakeholders within the system, data collection methods and analysis techniques may have provided further insight into the intricacies of norms or controversial aspects that could have constructed an alternative view of the system and its potential role.

The breadth of the issues acknowledged in this paper and the manner in which they are described in an integrated manner provides a rich narrative on the different issues at play. Indeed, a number of the issues covered by the analysis could benefit from focused inquiry such as how the historic development 
of the automobility system may generate path dependencies which shape its future, or how the trust relationships within the automotive market between manufacturers, citizens and governance institutions are shifting as a result of the perceived manufacturer manipulation of vehicle emissions. Indeed, significant value could be generated through repeating this analysis with other stakeholder groups as opposed to transport professionals in order to compare the salience of views. Equally, conducting a similar analysis in an alternative context would allow for considerations to be made regarding the degree to which the findings of this research are transferable to other settings (such as other countries) or are unique to British circumstances.

\section{Acknowledgements}

The authors would like to thank Cumberland Lodge for hosting the event, the participants of the focus groups for their valuable contributions, the reviewers of this paper who provided insightful comments as well as Lucy Mahoney and Dan Calverley for their assistance in conducting the focus groups. The views expressed are those of the authors and do not represent the views of the European Commission.

\section{References}

Banister, D. (2005). Unsustainable Transport: City Transport in the New Century: The Transport Crisis. London, UK: Routledge.

Banister, D. (2008). The sustainable mobility paradigm. Transport Policy, 15(2), pp.73-80.

Banister, D., \& Anable, J. (2009). Transport Policies and Climate Change. In Davoudi, S., Crawford, J., Mehmood, A., (Eds.) Planning for Climate Change: Strategies for Mitigation and Adaptation for Spatial Planners. Oxford, UK: Earthscan Publications Ltd.

Bastian, A., Börjesson, M., \& Eliasson, J. (2016). Explaining "peak car" with economic variables. Transportation Research Part A, 88, 236-250.

Beckmann, J. (2001). Automobility - a social problem and theoretical concept. Environment and Planning D: Society and Space, 19(5), pp.593- 607.

Böhm, S., Jones, C., Land, C., \& Paterson, M. (2006). Conceptualizing Automobility Introduction: Impossibilities of automobility. The Sociological Review, 54, 1-16. 
Cairns, S. (2011). Accessing Cars: Different ownership and use choices. Available at: http://www.racfoundation.org/assets/rac_foundation/content/downloadables/accessing_carscairns-main_report.pdf Accessed: $7^{\text {th }}$ September 2015.

Caniëls, M. C. J., \& Romijn, H. A. (2008). Strategic niche management: towards a policy tool for sustainable development. Technology Analysis \& Strategic Management, 20(2), 245-266.

Caperello, N. D., \& Kurani, K. S. (2012). Households' Stories of Their Encounters With a Plug-In Hybrid Electric Vehicle. Environment and Behavior, 44(4), 493-508.

Dant, T. (2004). The Driver-car. Theory, Culture \& Society, 21(4-5), pp.61-79.

Department for Transport (2014). Transport Statistics Great Britain: Table TSGB0101. Available at: https://www.gov.uk/government/statistics/transport-statistics-great-britain-2014 Accessed: $7^{\text {th }}$ September 2015.

Department for Transport (2015). National Transport Statistics: Table NTS0405. Available at: https://www.gov.uk/government/statistical-data-sets/nts04-purpose-of-trips Accessed: $7^{\text {th }}$ September 2015.

Dittmar, H. (1992). The Social Psychology of Material Possessions: To have is to be. New Jersey, USA: Prentice-Hall.

Dosi, G. (1982). Technological paradigms and technological trajectories. Research Policy, 11(3), pp.147-162.

Douglas, M. J., Watkins, S. J., Gorman, D. R., \& Higgins, M. (2011). Are cars the new tobacco? Journal of Public Health, 33(2), 160-169.

Dowling, R., \& Kent, j. (2013). The Challenges of Planning for Autonomous Mobility in Australia. State of Australian Cities Conference. Available at: http://www.soacconference.com.au/wpcontent/uploads/2013/12/Dowling-movement.pdf Accessed: $9^{\text {th }}$ August 2016. 
Dudley, G., \& Chatterjee, K. (2012). The governance of transport policy. In Geels, F., Kemp, R., Dudley, G., \& Lyons, G., (Eds.) Automobility in Transition? A socio-technical analysis of sustainable transport. London, UK: Routledge.

Dupuy, G. (1999). From the "magic circle" to "automobile dependence": measurements and political implications. Transport Policy. 6, pp. 1-17.

Eddington, R. (2006). The Eddington Transport Study: Volume 1 - Transport's role in sustaining the UK's productivity and competitiveness. Available at:

http://webarchive.nationalarchives.gov.uk/20090104005813/http://www.dft.gov.uk/162259/18760 4/206711/volume1.pdf Accessed: $7^{\text {th }}$ September 2015.

Egbue, O., \& Long, S. (2012). Barriers to widespread adoption of electric vehicles: An analysis of consumer attitudes and perceptions. Energy Policy, 48, 717-729.

Enoch, M. P. (2015). How a rapid modal convergence into a universal automated taxi service could be the future for local passenger transport. Technology Analysis \& Strategic Management, 27(8), 910-924

Environmental Protection Agency (2015). Notice of Violation. Available at: http://www3.epa.gov/otaq/cert/documents/vw-nov-2015-11-02.pdf, Accessed: $3^{\text {rd }}$ November 2015.

Featherstone, M. (2004). Automobilities: An Introduction. Theory, Culture \& Society, 21(4-5), pp.124.

Freudendal-Pedersen, M. (2007). Mobility, Motility and Freedom: The Structural Story as Analytical Tool for Understanding the Interconnection. Swiss Journal of Sociology, 33(1), 27-43.

Fontaras, G., Franco, V., Dilara, P., Martini, G., \& Manfredi, U. (2014). Development and review of Euro 5 passenger car emission factors based on experimental results over various driving cycles. Science of The Total Environment, 468-469, 1034-1042.

Frantzeskaki, N., Loorbach, D., \& Meadowcroft, J. (2012). Governing societal transitions to sustainability. International Journal of Sustainable Development, 15(1/2), 19-36. 
Gatersleben, B. (2011). The car as a material possession: Exploring the link between materialism and car ownership and use. In Lucas, K., Blumenber, E., Weinberger., R., (Eds.) Auto Motives: Understanding car use behaviours. Bingley, UK: Emerald publications.

Geels, F. W. (2012). A socio-technical analysis of low-carbon transitions: introducing the multi-level perspective into transport studies. Journal of Transport Geography, 24, 471-482.

Geerlings, H., Shiftan, Y., Stead, D. (2012). Transition towards sustainable mobility: The role of instruments, individuals and institutions. Farnham, UK: Ashgate publications.

Goldman, T. \& Gorham, R. (2006). Sustainable urban transport: Four innovative directions. Technology in Society, 28(1-2), pp.261-273.

Graham-Rowe, E., Gardner, B., Abraham, C., Skippon, S., Dittmar, H., Hutchins, R., \& Stannard, J. (2012). Mainstream consumers driving plug-in battery-electric and plug-in hybrid electric cars: A qualitative analysis of responses and evaluations. Transportation Research Part A: Policy and Practice, 46(1), 140-153.

Guest, G.S., Namey, E.E. \& Mitchell, M.L. (2012). Collecting Qualitative Data: A Field Manual for Applied Research, Thousand Oaks, USA: SAGE Publications.

Gärling, T., Gärling, A. \& Loukopoulos, P. (2002). Forecasting Psychological Consequences of Car Use Reduction: A Challenge to an Environmental Psychology of Transportation. Applied Psychology, 51(1), pp.90-106.

Gössling, S., \& Cohen, S. (2014). Why sustainable transport policies will fail: EU climate policy in the light of transport taboos. Journal of Transport Geography, 39, 197-207.

Henderson, J. (2006). Secessionist automobility: Racism, anti-urbanism, and the politics of automobility in Atlanta, Georgia. International Journal of Urban and Regional Research, 30(2), 293307.

Hickman, R. \& Banister, D. (2007). Looking over the horizon: Transport and reduced CO2 emissions in 
the UK by 2030. Transport Policy, 14(5), pp.377-387

Hopkins, D. (2016a). Can environmental awareness explain declining preference for car-based mobility amongst generation $\mathrm{Y}$ ? A qualitative examination of learn to drive behaviours. Transportation Research Part A: Policy and Practice, 94, 149-163. https://doi.org/10.1016/i.tra.2016.08.028

Hopkins, D. (2016b). Destabilising automobility? The emergent mobilities of generation Y. Ambio, 113. https://doi.org/10.1007/s13280-016-0841-2

Hubers, C. \& Lyons, G. (2013). Assessing future travel demand: a need to account for non-transport technologies? Foresight, 15(3), 211-227

Kent, J.L. \& Dowling, R. (2013). Puncturing automobility? Carsharing practices. Journal of Transport Geography, 32, pp.86-92.

Kent, J. L. (2015). Still Feeling the Car - The Role of Comfort in Sustaining Private Car Use. Mobilities, 10(5), 726-747.

Kemp, R., Schot, J. \& Hoogma, R. (1998). Regime shifts to sustainability through processes of niche formation: The approach of strategic niche management. Technology Analysis \& Strategic Management, 10(2), pp.175-198.

Kemp, R., Geels, F., \& Dudley, G. (2012). Sustainability transitions in the automobility regime and the need for a new perspective. In Geels, F., Kemp, R., Dudley, G., \& Lyons, G., (Eds.) Automobility in Transition? A socio-technical analysis of sustainable transport. London, UK: Routledge.

Ker, I., \& Tranter, P., (1997). A wish called wander: reclaiming automobility from the motor car. World Transport Policy and Practice, 3, pp. 11-16.

Kley, F., Lerch, C. \& Dallinger, D. (2011). New business models for electric cars-A holistic approach. Energy Policy, 39(6), pp.3392-3403. 
Kuhnimhof, T., Armoogum, J., Buelher, R., Dargay, J., Denstadli, J. M., \& Yamamoto, T. (2012). Men shape a downward trend in car use among young adults - evidence from six industrialised countries. Transport Reviews, 32 (6), 761-799.

Kurani, K. S., Turrentine, T., \& Sperling, D. (1996). Testing electric vehicle demand in 'hybrid households' using a reflexive survey. Transportation Research Part D: Transport and Environment, 1(2), 131-150.

Loorbach, D. (2010). Transition Management for Sustainable Development: A Prescriptive, Complexity-Based Governance Framework. Governance, 23(1), 161-183.

Lyons, G. (2012). Visions for the Future and the Need for a Social Science Perspective in Transport Studies. In Geels, F., Kemp, R., Dudley, G., \& Lyons, G., (Eds.) Automobility in Transition? A sociotechnical analysis of sustainable transport. London, UK: Routledge.

Lyons, G., \& Goodwin, P. (2014). Grow, peak or plateau - the outlook for car travel. Discussion Paper. New Zealand Ministry of Transport.

Lucas, K., \& Jones, P. (2009). The car in British society. Royal automobile club foundation publication. Available at:

http://www.racfoundation.org/assets/rac_foundation/content/downloadables/car_in_british_societ y-lucas_et_al-170409.pdf Accessed: $7^{\text {th }}$ September 2015.

Mattioli, G. (2014). Moving through the city with strangers? Public transport as a significant kind of urban public space. In Shortell, T., \& Brown, E., (Eds.) Walking in the European City: Quotidian Mobility and Urban Ethnography. Farnham, UK: Ashgate publications.

Mattioli, G., Anable, J., \& Vrotsou, K. (2016). Car dependent practices: Findings from a sequence pattern mining study of UK time use data. Transportation Research Part A, 89, 56-72.

Martens, K. (2012). Justice in transport as justice in accessibility: applying Walzer's "Spheres of Justice" to the transport sector. Transportation. 39(6), pp.1035-1053. 
Moriarty, P. \& Honnery, D. (2008). The prospects for global green car mobility. Journal of Cleaner Production, 16(16), pp.1717-1726.

Mullen, C., \& Marsden, G. (2016). Mobility justice in low carbon energy transitions. Energy Research and Social Science.

Nykvist, B. \& Whitmarsh, L. (2008). A multi-level analysis of sustainable mobility transitions: Niche development in the UK and Sweden. Technological Forecasting and Social Change, 75(9), pp.13731387.

O'Sullivan, D. (2004). Complexity science and human geography. Transactions of the Institute of British Geographers, 29(3), pp.282-295.

Pooley, C. (2016). Mobility, Transport and Social Inclusion: Lessons from History. Social Inclusion, 4(3), 100-109.

RAC Foundation (2006). Shopping and transport policy. London, UK: Royal Automobile Club Foundation publication.

Royal Academy of Engineering (2011). Engineering Ethics in Practise: a guide for engineers. London, Royal Academy of Engineering.

Rajan, C. (2007). Automobility, Liberalism, and the Ethics of Driving. Environmental Ethics. 29, pp. 7790.

Safdie, M. (1998). The City After The Automobile: An Architect's Vision, Boulder, USA: Perseus.

Sanderson, I. (2002). Evaluation, Policy Learning and Evidence-Based Policy Making. Public Administration, 80(1), pp.1-22.

Schot, J., Hoogma, R. \& Elzen, B. (1994). Strategies for shifting technological systems: The case of the automobile system. Futures, 26(10), pp.1060-1076. 
Schot, J., \& Geels, F. W. (2008). Strategic niche management and sustainable innovation journeys: theory, findings, research agenda, and policy. Technology Analysis \& Strategic Management, 20(5), $537-554$.

Shaheen, S. A., \& Cohen, A. P. (2013). Carsharing and Personal Vehicle Services: Worldwide Market Developments and Emerging Trends. International Journal of Sustainable Transportation, 7(1), 5-34.

Sheller, M. (2004). Automotive Emotions Feeling the Car.Theory, Culture \& Society, 21(4-5), pp.221242.

Sileghem, L., Bosteels, D., May, J., Favre, C., \& Verhelst, S. (2014). Analysis of vehicle emission measurements on the new WLTC, the NEDC and the CADC. Transportation Research Part D: Transport and Environment. 32, pp. 70-85.

Smith, A., Stirling, A., \& Berkhout, F. (2005). The governance of sustainable socio-technical transitions. Research Policy, 34(10), 1491-1510.

Social Exclusion Unit (2003). Making the connections: final report on transport and social exclusion. London: Office of the Deputy Prime Minister.

Spence, A., Poortinga, W. \& Pidgeon, N. (2012). The Psychological Distance of Climate Change. Risk Analysis, 32(6), pp.957-972.

Steg, L. (2005). Car use: lust and must. Instrumental, symbolic and affective motives for car use. Transportation Research Part A: Policy and Practice, 39(2-3), 147-162.

Steinhilber, S., Wells, P., \& Thankappan, S. (2013). Socio-technical inertia: Understanding the barriers to electric vehicles. Energy Policy, 60, 531-539.

Tran, M., Banister, D., Bishop, J. D. K., \& McCulloch, M. D. (2013). Simulating early adoption of alternative fuel vehicles for sustainability. Technological Forecasting and Social Change, 80(5), 865875.

Urry, J. (2004). The "System" of Automobility. Theory, Culture \& Society, 21(4-5), pp.25-39. 
Urry, J. (2007). Mobilities. Cambridge, UK; Malden, MA: Polity.

Vergragt, P.J. \& Brown, H.S. (2007). Sustainable mobility: from technological innovation to societal learning. Journal of Cleaner Production, 15(11-12), pp.1104-1115.

Vermaas, P., Kroes, P., van de Poel, I., Franssen M. \& Houkes, W. (2011). A Philosophy of Technology - From technical artefacts to Sociotechnical Systems, Morgan and Claypool.

Waygood, E.O.D., Avineri, E. (2011). Does "500g of CO2 for a five mile trip" mean anything? Towards more effective presentation of $\mathrm{CO} 2$ information. Proceedings of the Transportation Research Board 90th Annual Meeting, Washington, D.C.

Wesseling, J.H., Farla, J.C.M. \& Hekkert, M.P. (2015). Exploring car manufacturers' responses to technology-forcing regulation: The case of California's ZEV mandate. Environmental Innovation and Societal Transitions.

Whitmarsh, L., Swartling, Å.G. \& Jäger, J. (2009). Participation of experts and non-experts in a sustainability assessment of mobility. Environmental Policy and Governance, 19(4), pp.232-250.

Wong, N.Y., \& Ahuvia, A.C. (1998). Personal taste and family face: Luxury consumption in Confucian and Western societies. Psychology and Marketing, 15(5), pp.423-441.

Wright, C. \& Egan, J. (2000). De-marketing the car. Transport Policy, 7(4), pp.287-294. 